\title{
Size-exclusion liquid chromatography for effective purification of amphiphilic trinuclear gold(I) pyrazolate complex
}

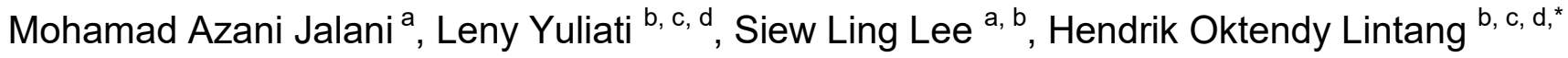 \\ a Department of Chemistry, Faculty of Science, Universiti Teknologi Malaysia, 81310 UTM Johor Bahru, Johor, Malaysia \\ ${ }^{b}$ Centre for Sustainable Nanomaterials, Ibnu Sina Institute for Scientific and Industrial Research, Universiti Teknologi Malaysia, 81310 UTM Johor \\ Bahru, Johor, Malaysia \\ Ma Chung Research Center for Photosynthetic Pigments, Universitas Ma Chung, Malang 65151, East Java, Indonesia \\ ${ }^{d}$ Department of Chemistry, Faculty of Science and Technology, Universitas Ma Chung, Malang 65151, East Java, Indonesia \\ *Corresponding author: hendrik.lintang@machung.ac.id
}

Article history

Submitted 19 December 2017

Revised 19 March 2018

Accepted 31 March 2018

Published Online 30 April 2018

\section{Graphical abstract}

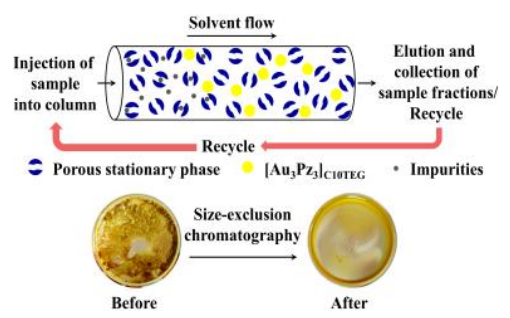

\begin{abstract}
Column gravity chromatography suffered from several drawbacks such as time-consuming and needed a large number of eluents. Herein we reported an efficient technique for effective separation of amphiphilic trinuclear gold $(I)$ pyrazolate complex $\left(\left[\mathrm{Au}_{3} \mathrm{Pz}_{3}\right]_{\mathrm{C} 10 \mathrm{TEG}}\right)$ with high polarity based on the size-exclusion principle of chromatography technique. Based on the size-exclusion limit, $\left[\mathrm{Au}_{3} \mathrm{Pz}_{3}\right]_{\mathrm{C} 10 T E G}$ having a larger size with a molecular weight of $4011.39 \mathrm{Da}(4030.40 \mathrm{Da}$ when added $\mathrm{Na}^{+}$) was successfully eluted and collected firstly from its impurities after being recycled for two times. In the chromatogram for the first cycle, an intense peak upon excitation at $220 \mathrm{~nm}$ for $\left[\mathrm{Au}_{3} \mathrm{Pz}_{3}\right]_{\text {C10TEG }}$ was observed at a retention time of $58 \mathrm{mins}$, while small peaks due to the presence of impurities were observed in the range between 73 to 85 mins. In the second cycle, the impurities were flushed away before $\left[\mathrm{Au}_{3} \mathrm{Pz}_{3}\right]_{\mathrm{C} 10 T E G}$ was successfully collected at a retention time of $170 \mathrm{mins}$ in the third cycle. The columns were a set of polystyrene/divinylbenzene (PS/DVB) JAIGEL-1H and $2.5 \mathrm{H}$ connected in series having exclusion limit of $1 \times 10^{3}$ and $2 \times 10^{4} \mathrm{Da}$ in which chloroform was used as the eluent at a flow rate of $3.5 \mathrm{~mL} \mathrm{~min}^{-1}$. As a result, the visual appearance of dark-yellowish $\left[\mathrm{Au}_{3} \mathrm{Pz}_{3}\right]_{\text {C10TEG }}$ was successfully purified to give the pale-yellowish product. Moreover, differential scanning calorimetry thermogram showed that extra shoulder from impurities at $6.13^{\circ} \mathrm{C}$ in the first endothermic peak of $\left[\mathrm{Au}_{3} \mathrm{Pz}_{3}\right]_{\text {C10TEG }}$ at $0.76{ }^{\circ} \mathrm{C}$ was completely removed. Hence, it can be concluded that size-exclusion chromatography can be used as an effective purification method with much more convenience and small consumption of solvents.
\end{abstract}

Keywords: Gold(I) pyrazolate complex, purification, recycle, size-exclusion chromatography

\section{INTRODUCTION}

In supramolecular chemistry, the types of interactions such as hydrogen bonding, $\pi-\pi$ stacking, and metal-metal interactions are very important for designing a polymeric structure system (Hadjichristidis et al. 2011). In particular, the metal-metal interaction is classified as a direct interaction between two or more metal atoms that is weaker than covalent or ionic bonds, but stronger than Van der Waal interaction. In a gold system, the metal-metal interaction is referred as an aurophilic interaction that is crucial in aggregation and selfassembly of gold complexes (Schmidbaur, 2000). On the other hand, gold also can form a cyclic trinuclear system by utilizing an exobidentate ligand such as pyrazole where three gold(I) ions are bridged by $\mathrm{N}, \mathrm{N}$ donor molecules to produce gold(I) pyrazolate complex. Pyrazole ligands have gained much attention in many types of research due to their versatile coordination chemistry. This versatility includes that the ligand can work as both monodentate (neutral or anionic) or bidentate (exo or endo anionic) systems (Trofimenko, 1972), hence making it suitable for designing a supramolecular structure containing multimetal coordination complex (La and Ardizzoia, 1997). Moreover, trinuclear cyclic gold(I) pyrazolate complexes have been widely utilized in many applications such as liquid crystals (Barbera et al., 1996; Kim et al., 1998; Torralba et al., 2004), metal ion sensors (Kishimura et al., 2005; Lintang et al., 2012a), template for synthesis of mesoporous silica (Lintang et al., 2010a; Lintang et al., 2010b; Lintang et al., 2011; Lintang et al., 2012b; Lintang et al., 2014) and as metal source for formation of gold nanoparticles (Jalani et al., 2014a; Jalani et al., 2014b). Therefore, it is very important to have an effective purification and separation method for the synthesis of gold(I) pyrazolate complex with high purity to ensure efficient performance in respective applications.

Chromatography is a common technique that was widely used for purification and separation of materials especially organic compounds. Chromatography can be defined as a separation of two or more different compounds or ions based on their distribution in certain stationary and mobile (moving) phases (Vékey et al., 2008). In particular, column gravity chromatography (CGC) is a conventional and useful technique for the purification of compounds on both small and large scale. As this technique is highly dependent on adsorptivity and solubility factors, several parameters such as the type of adsorbent (stationary phase), the polarity of solvents (mobile phase), size of column and rate of elution must be carefully chosen (Pavia et al., 2011). Generally, the adsorbent that was selected as stationary phase must not dissolve the associated solvent (mobile phase). The two most commonly used stationary phases are silica gel and alumina where these compounds usually exist in a powdered or finely grounded form. In principle, non-polar compounds will elute the CGC much faster compared to polar compounds due to their low affinity or less 
interaction with the stationary phase. However, although this technique was extensively used in many purification and separation of organic or organometallic compounds, it still suffered from several drawbacks such as time-consuming, need a large amount of eluents and difficult to distinct two or more molecules with almost same polarity (Pelletier et al., 1986; Targett et al., 1979).

On the other hand, size-exclusion chromatography (SEC) is another popular method that was used for effective purification and separation of organic compounds. In contrast to CGC that separates the molecules based on their polarity, SEC carries out the separation process based on the size (hydrodynamic volume) of the compounds (Vékey et al., 2008). The stationary phase in SEC usually is made up of cross-linked polymeric materials having a porous structure and packing in the stainless steel column. Throughout the separation process, the molecules will permeate the stationary phase with the help of solvent as the mobile phase, where small size molecules will penetrate the porous structure much easily compared to large ones. Thus, large molecules will be eluted and collected first as they are able to move through the column much faster compared to the smaller one (Pavia et al., 2011). In addition, a more modern SEC technique hyphenated with a recycling feature (recycle valve) was introduced in order to further improve the separation efficiency. This combination allowed the complete separation of two or more compounds with different molecular sizes carried in the mobile phase by repeatedly cycling within the same column. The recycling SEC also possessed several advantages such as lower consumption of eluents during the analysis, better separation of compounds with each cycle and reduce the cost as it does not require a longer column (Sidana and Joshi, 2013). In this work, by using recycling SEC for the purification and isolation of amphiphilic trinuclear gold(I) pyrazolate complex bearing nine triethylene glycol and $\mathrm{C} 10$-carbon chain $\left(\left[\mathrm{Au}_{3} \mathrm{Pz}_{3}\right]_{\mathrm{ClOTEG}}\right)$ with high polarity, it was found that not only the separation technique was highly convenient and only utilized smaller amount of solvents, but it also allowed a higher quantity of interested compound being collected at the end of analysis due to its non-interaction properties of the system with the compound. Moreover, as the sample purity determination based on nuclear magnetic resonance (NMR) and Fourier-transform infrared (FTIR) spectroscopies have been successfully reported in our previous works (Jalani et al., 2014b; Lintang et al., 2010a), differential scanning calorimetry (DSC) was utilized in this work to further demonstrate the purity of sample from any impurities (DeAngelis et al., 1968; Plato and Glasgow, 1969; Plato, 1972).

\section{EXPERIMENTAL}

\section{General}

In this work, all the chemicals and reagents with an analytical grade from Sigma-Aldrich brands were used in the reaction including the anhydrous solvents. The differential scanning calorimetry (DSC) measurement was carried out by using METTLER TOLEDO model DSC 822e within range of $-40{ }^{\circ} \mathrm{C}$ in crystallization temperature to 80 ${ }^{\circ} \mathrm{C}$ in isotropic temperature. Throughout the DSC analysis, the sample was heated and cooled at the rate of $10{ }^{\circ} \mathrm{C} \mathrm{min}$. The exact molecular weight of samples was determined by using time-of-flight mass spectrometer with laser desorption-ionization technique (MALDITOF-MS) from Applied Biosystem (AB) Sciex model 5800 in reflection mode and ion positive ionization technique. The sample preparation was done by spotting the sample $(2 \mu 1)$ onto a conductive plate containing the desired matrix for crystallization process to occur. The matrixes that can be used were either $\alpha$-cyano-4hydroxycinnamic acid (CHCA) or dithranol, where both matrixes are prepared in chloroform. In the purification step via CGC, 40-100 mesh of pure sand from Acros Organics and 70-230 mesh of silica gel $60(0.063-0.200 \mathrm{~mm})$ from Merck Millipore were used for the preparation of the column. For purification and isolation of high purity of the sample, recycling SEC using Japan Analytical Industry Recycling High Performance Liquid Chromatography (HPLC) model LC-9110II NEXT was performed. The HPLC was equipped with a variable-wavelength UV-vis detector (UV-600) and chloroform
$\left(\mathrm{CHCl}_{3}\right)$ flowed as a mobile phase of the sample at $3.5 \mathrm{~mL} \mathrm{~min} \mathrm{mi}^{-1}$ throughout the instrument. For the best separation of the sample injected, the columns used were a set of polystyrene/divinylbenzene (PS/DVB) JAIGEL-1H and $-2.5 \mathrm{H}$ connected in series with an exclusion limit of $1 \times 10^{3}$ and $2 \times 10^{4} \mathrm{Da}$, respectively. The diagram for illustration of both CGC and recycling SEC is shown in Fig. 1.

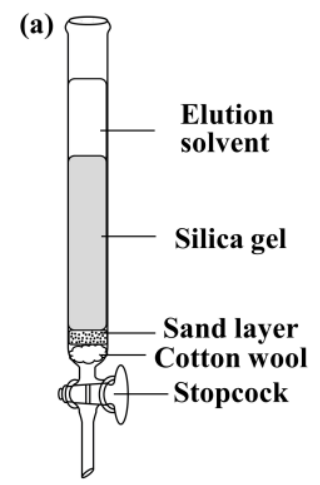

(b)

Fig. 1 Diagram illustration for (a) column gravity and (b) recycling sizeexclusion chromatographies.

\section{Synthesis and purification of $\left[\mathrm{Au}_{3} \mathrm{Pz}_{3}\right]_{\mathrm{C} 10 T E G}$}

A solution of pyrazole ligand $\left(\mathrm{C}_{10} \mathrm{TEGPzH}, 300.00 \mathrm{mg}, 0.26\right.$ $\mathrm{mmol})$ dissolved in dry tetrahydrofuran $(20.00 \mathrm{~mL})$ was prepared in a Schlenk flask after being vacuumed and flowed under $\mathrm{N}_{2}$ gas environment. Later, $\mathrm{Au}\left(\mathrm{SMe}_{2}\right) \mathrm{Cl}$ salt $(77.00 \mathrm{mg}, 0.26 \mathrm{mmol})$ was added to the flask and stirred for 10 minutes. Furthermore, a solution of potassium hydroxide $(\mathrm{KOH} ; 0.26 \mathrm{M}, 0.014 \mathrm{~g})$ in dry methanol $(1.00 \mathrm{~mL})$ was prepared and added dropwise to the flask using a Schlenk technique under continuous $\mathrm{N}_{2}$ flow. The resulting mixture was left to stir for overnight. After the completion of the reaction, the mixture was filtered via in-situ filtration for any insoluble solids. The collected solution was transferred to a flask and evaporated to dryness in order to remove the solvent. The residue was firstly purified by using CGC where silica gel was used as the stationary phase and ethyl acetate/methanol solvent in a ratio of 10:1 was used as the mobile phase to give $\left[\mathrm{Au}_{3} \mathrm{Pz}_{3}\right]_{\mathrm{C} 10 \mathrm{TEG}} / \mathrm{CGC}$ as a dark-yellow sticky solid with $60 \%$ yield $(210.00 \mathrm{mg}, 0.05 \mathrm{mmol})$. Later, the fraction was further purified by using recycling SEC in which sample was pre-filtered using $0.25 \mu \mathrm{m}$ membrane filter in chloroform. The sample was injected using a syringe in $3 \mathrm{~mL}$ of chloroform to the column to give $\left[\mathrm{Au}_{3} \mathrm{Pz}_{3}\right]_{\mathrm{C} 10 \mathrm{TEG}} / \mathrm{SEC}$ as a pale-yellow sticky solid $(150.00 \mathrm{mg}, 0.03$ mmol).

\section{RESULTS AND DISCUSSION}

\section{Effective purification of $\left[\mathrm{Au}_{3} \mathrm{Pz}_{3}\right]_{\text {C10TEG }}$ via recycling size- exclusion chromatography}

In the purification stage, $\left[\mathrm{Au}_{3} \mathrm{Pz}_{3}\right]_{\mathrm{C} 10 \mathrm{TEG}}$ was successfully purified via CGC and SEC techniques. However, it was found that after CGC, a dark-yellowish $\left[\mathrm{Au}_{3} \mathrm{Pz}_{3}\right]_{\mathrm{C} 10 \mathrm{TEG}}$ as shown in Fig. 2(a) was obtained, indicating the presence of impurities along with the gold complex. Moreover, based on the use of thin layer chromatography (TLC), this also indicated that it is quite difficult to get a good separation of compounds with high and same polarity to the impurities and or remaining reactants upon using CGC due to the several parameters such as adsorbent chosen, the polarity strength of solvents used, size of column and rate of elution throughout the process as mentioned earlier. Interestingly, after $\left[\mathrm{Au}_{3} \mathrm{Pz}_{3}\right]_{\text {C10TEG }}$ was further purified by using recycling SEC, a pale-yellowish solid was successfully collected as shown in Fig. 2(b). This observation proved that the SEC is an effective technique for easy purification and good separation of $\left[\mathrm{Au}_{3} \mathrm{Pz}_{3}\right]_{\mathrm{C} 10 \mathrm{TEG}}$ from its impurities. Based on the SEC chromatogram as shown in Fig. 3, $\left[\mathrm{Au}_{3} \mathrm{Pz}_{3}\right]_{\mathrm{C} 10 \mathrm{TEG}}$ was successfully eluted and collected firstly from its impurities after being recycled for two times. The collection of the product was immediately made after its UV peak in the chromatogram was clearly separated from other impurities. In 
the chromatogram for the first cycle, an intense peak upon excitation at $220 \mathrm{~nm}$ for $\left[\mathrm{Au}_{3} \mathrm{Pz}_{3}\right]_{\mathrm{ClOTEG}}$ was observed at a retention time of 58 mins, while small peaks due to the presence of impurities were observed in the range between 73 to 85 mins. Both the peaks due to $\left[\mathrm{Au}_{3} \mathrm{Pz}_{3}\right]_{\mathrm{C} 10 \mathrm{TEG}}$ and expected impurities were recycled in order to get a better separation. Otherwise, the impurities can be removed as a drain for the selected retention time for each cycle. Moreover, the precise observation for the absorption peak at several selected wavelengths to identify the presence of desired compounds and unwanted impurities can be performed for efficient purification compared to CGC that using UV hand-held lamp at 254 or $365 \mathrm{~nm}$ for checking the spot. Hence, during the second cycle, the impurities were fractioned and flushed away as the drain before $\left[\mathrm{Au}_{3} \mathrm{Pz}_{3}\right]_{\mathrm{ClOTEG}}$ was successfully collected at a retention time of 170 mins in the third cycle. As a result, the visual appearance of dark-yellowish $\left[\mathrm{Au}_{3} \mathrm{Pz}_{3}\right]_{\mathrm{C10TEG}}$ was successfully purified and isolated to give the pale-yellowish product.

(a)

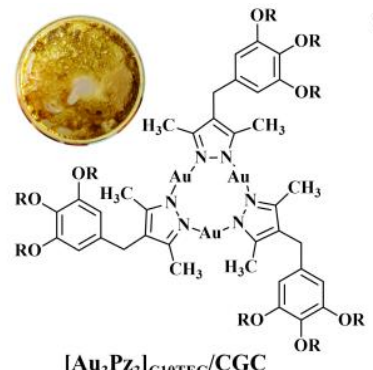

Hydrophobic (b)

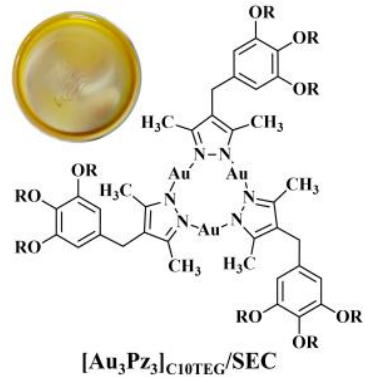

Hydrophilic

$\mathbf{R}=\mathbf{C 1 0 T E G}=$

Fig. 2 The chemical structure and visual appearance of $\left[\mathrm{Au}_{3} \mathrm{Pz}_{3}\right]_{\mathrm{C} 10 \mathrm{TEG}}$ with (a) dark-yellowish color after CGC and (b) pale-yellowish color after recycling SEC.

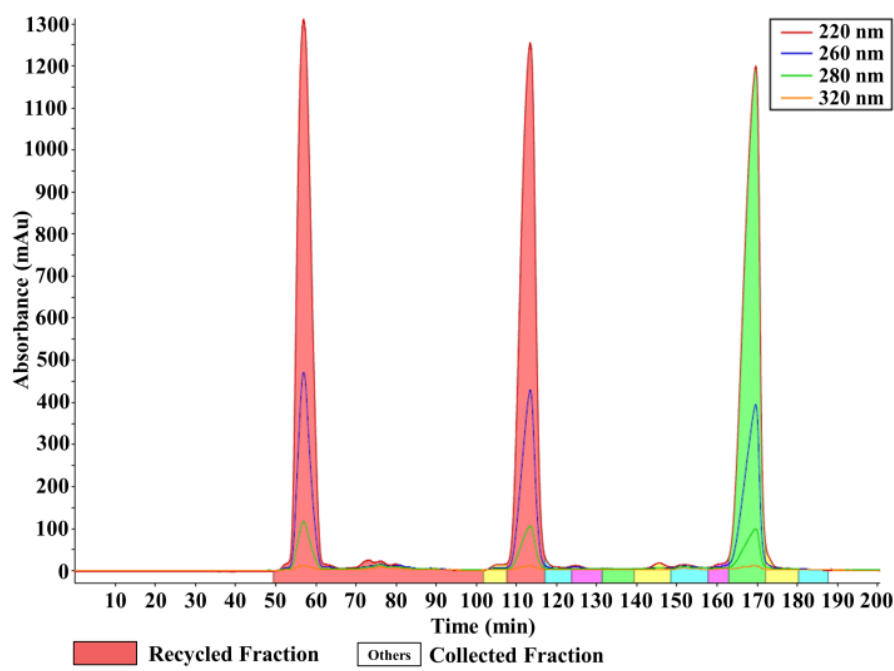

Fig. 3 SEC chromatogram of $\left[\mathrm{Au}_{3} \mathrm{P}_{3}\right]_{\mathrm{C} 10 \mathrm{TEG}}$ up to three cycles detected at several wavelengths of 220, 260, 280 and $320 \mathrm{~nm}$ within 200 mins.

The mechanism for the separation of $\left[\mathrm{Au}_{3} \mathrm{Pz}_{3}\right]_{\mathrm{C} 10 \mathrm{TEG}}$ from its impurities can be illustrated as proposed in Fig. 4. Since the stationary phase of SEC was made up of cross-linked polymeric material with a porous structure, the injected compounds can be easily separated based on their size and ability to penetrate the column. By referring to SEC chromatogram in Fig. 3 , the peak of $\left[\mathrm{Au}_{3} \mathrm{Pz}_{3}\right]_{\mathrm{C} 10 \mathrm{TEG}}$ was observed first to indicate that the gold complex was having the largest size in the domain. Therefore, the $\left[\mathrm{Au}_{3} \mathrm{Pz}_{3}\right]_{\mathrm{C} 10 \mathrm{TEG}}$ can move through the column much faster compared to its impurities. In addition, the impurities were shown to have a small size based on its longer retention time to penetrate the porous structure. By increasing the number of cycles, both $\left[\mathrm{Au}_{3} \mathrm{Pz}_{3}\right]_{\mathrm{C} 10 \mathrm{TEG}}$ and the impurities will move much further between each other, hence it can give a better separation.

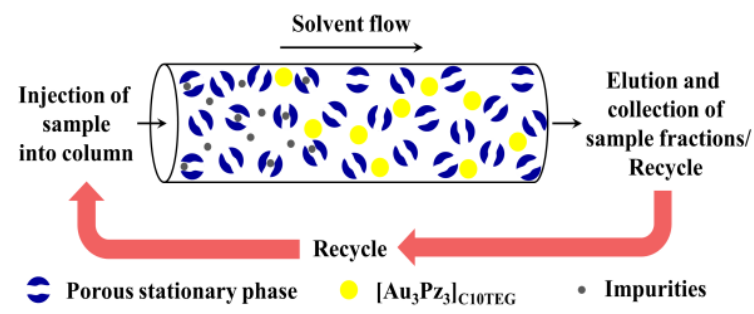

Fig. 4 The comparison for movement of $\left[\mathrm{Au}_{3} \mathrm{P} \mathrm{z}_{3}\right]_{\mathrm{C} 10 \mathrm{TEG}}$ with large size and its impurities having smaller size through the column.

\section{Purity Determination of $\left[\mathrm{Au}_{3} \mathrm{Pz}_{3}\right]_{\mathrm{C} 10 \mathrm{TEG}}$}

The presence of impurities in the compound can be determined by inspecting the DSC thermogram of $\left[\mathrm{Au}_{3} \mathrm{Pz}_{3}\right]_{\mathrm{C} 10 \mathrm{TEG}}$ for any anomalous peaks. After the CGC technique, DSC thermogram in Fig. 5(a) showed the presence of extra shoulder at $6.13{ }^{\circ} \mathrm{C}$ due to impurities in the first endothermic peak at $0.76^{\circ} \mathrm{C}$. Although the sample was heated for the second heating-cooling cycle, the extra shoulder still remained in the thermogram. Interestingly, when $\left[\mathrm{Au}_{3} \mathrm{Pz}_{3}\right]_{\mathrm{C} 10 \mathrm{TEG}}$ was further purified by using recycling SEC, the extra shoulder from impurities was completely removed as shown in Fig. 5(b). Moreover, the presence of impurities also shifted the temperature for complete melting to lower temperature at 42.28 and $37.62{ }^{\circ} \mathrm{C}$ (Fig. 5(a)) compared to pure compound at 52.75 and $50.00{ }^{\circ} \mathrm{C}$ (Fig. 5(b)). By having higher purity, the liquid crystalline properties exhibited by $\left[\mathrm{Au}_{3} \mathrm{Pz}_{3}\right]_{\mathrm{C} 10 \mathrm{TEG}}$ can also be studied through the DSC analysis.
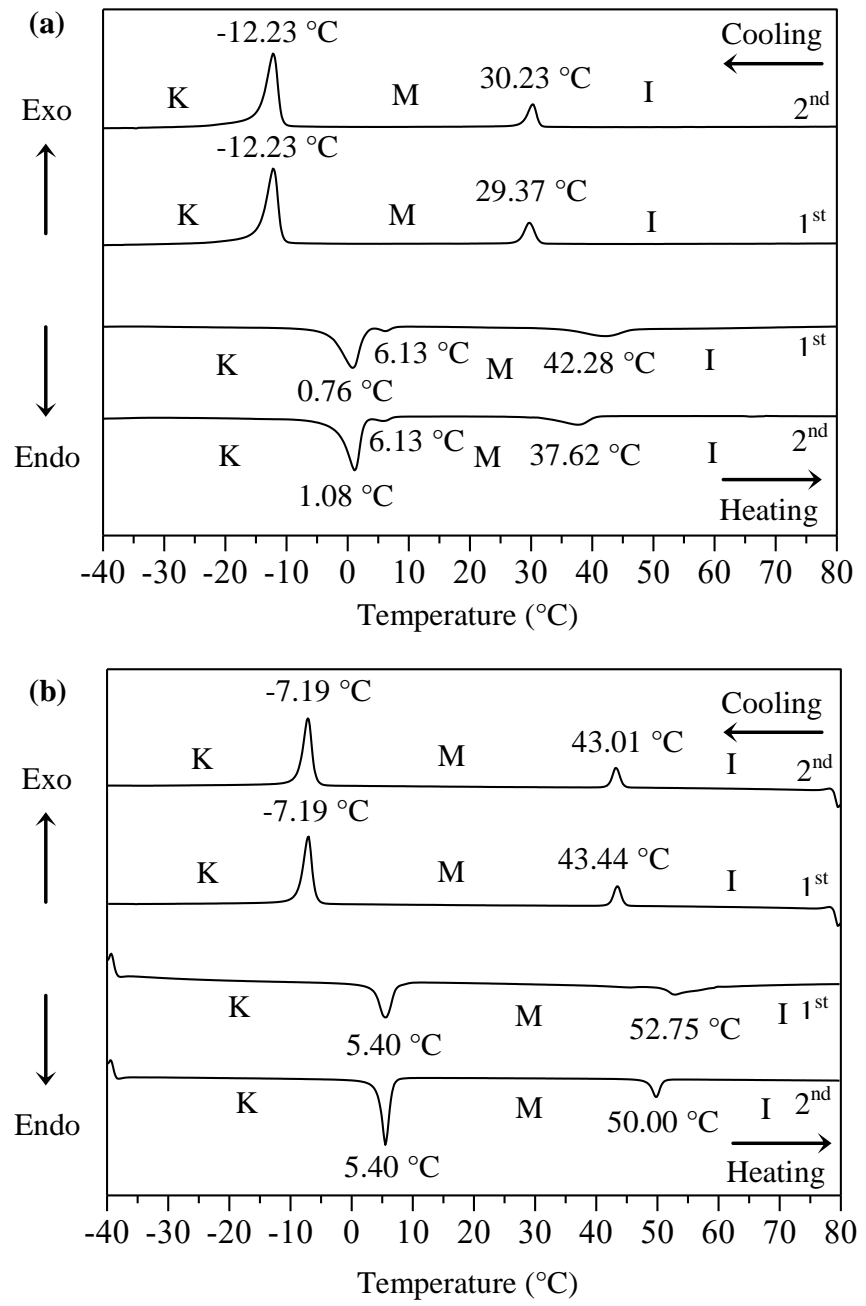

Fig. $5 \mathrm{DSC}$ thermogram of $\left[\mathrm{Au}_{3} \mathrm{Pz}_{3}\right]_{\mathrm{C} 10 \mathrm{TEG}}$ upon first and second heating-cooling cycles from -40 to $80^{\circ} \mathrm{C}$ at $10^{\circ} \mathrm{C} \mathrm{min}{ }^{-1}$ of (a) after CGC and (b) after recycling SEC where K: crystalline, M: mesophase and I: isotropic. 
Based on the first heating-cooling cycle in Fig. 5(b), the DSC thermogram clearly proved the liquid crystalline property of $\left[\mathrm{Au}_{3} \mathrm{Pz}_{3}\right]_{\mathrm{C} 10 \mathrm{TEG}}$ with a mesophase range from 5.40 to $52.75{ }^{\circ} \mathrm{C}(\Delta \mathrm{T}=$ $\left.47.35{ }^{\circ} \mathrm{C}\right)$ upon heating and 43.44 to $-7.19{ }^{\circ} \mathrm{C}\left(\Delta \mathrm{T}=50.63{ }^{\circ} \mathrm{C}\right)$ upon cooling from its hot melt. Upon first heating, $\left[\mathrm{Au}_{3} \mathrm{Pz}_{3}\right]_{\mathrm{C} 10 \mathrm{TEG}}$ in its crystalline phase below $5.40{ }^{\circ} \mathrm{C}$ started to show a liquid crystalline phase from 5.50 until $52.75{ }^{\circ} \mathrm{C}$ before going to full isotropic melt upon further heating. During the first cooling, an exothermic peak at $43.44{ }^{\circ} \mathrm{C}$ was appeared due to the rearrangement of their amphiphilic side chains and recovery of the strong $\mathrm{Au}(\mathrm{I})-\mathrm{Au}(\mathrm{I})$ interaction before another exothermic peak at $-7.19{ }^{\circ} \mathrm{C}$ was observed as it entered the crystalline phase. The first cycle proved that $\left[\mathrm{Au}_{3} \mathrm{Pz}_{3}\right]_{\mathrm{C} 10 \mathrm{TEG}}$ was able to recover its phase and structural arrangement after the heating and cooling cycle. Later, the same result also being shown in the second heating-cooling cycle and expected to remain even after being heated and cooled for few times. In principle, $\left[\mathrm{Au}_{3} \mathrm{Pz}_{3}\right]_{\mathrm{C} 10 \mathrm{TEG}}$ belongs to thermotropic type as it showed a phase transition into liquid crystal upon temperature changes. In addition, $\left[\mathrm{Au}_{3} \mathrm{Pz}_{3}\right]_{\mathrm{C} 10 \mathrm{TEG}}$ was also categorized as an enantiotropic liquid crystal as it can exhibit mesogenic properties by both upon lowering the temperature of a liquid or increasing the temperature of a solid. Likewise, the roomtemperature liquid crystalline properties exhibited by $\left[\mathrm{Au}_{3} \mathrm{Pz}_{3}\right]_{\mathrm{C} 10 \mathrm{TEG}}$ as measured by DSC showed a very stable baseline compared to other reported works (Kumar and Varshney, 2000; Liu et al., 2003; Luo et al., 2009; Sakurai et al., 2011; Sato et al., 2011; van Herrikhuyzen et al., 2004).

On the other hand, the molecular weight of $\left[\mathrm{Au}_{3} \mathrm{Pz}_{3}\right]_{\mathrm{C} 10 \mathrm{TEG}}$ with a molecular formula of $\mathrm{C}_{189} \mathrm{H}_{345} \mathrm{Au}_{3} \mathrm{~N}_{6} \mathrm{O}_{45}$ for $[\mathrm{M}+\mathrm{Na}]^{+}$was shown at 4033.40 Da as depicted in Fig. 6(a). The result was compared to the theoretical value of $4033.37 \mathrm{Da}$ (Fig. 6(b)), where it was close to each other and the isotopic pattern was also found to be similar.
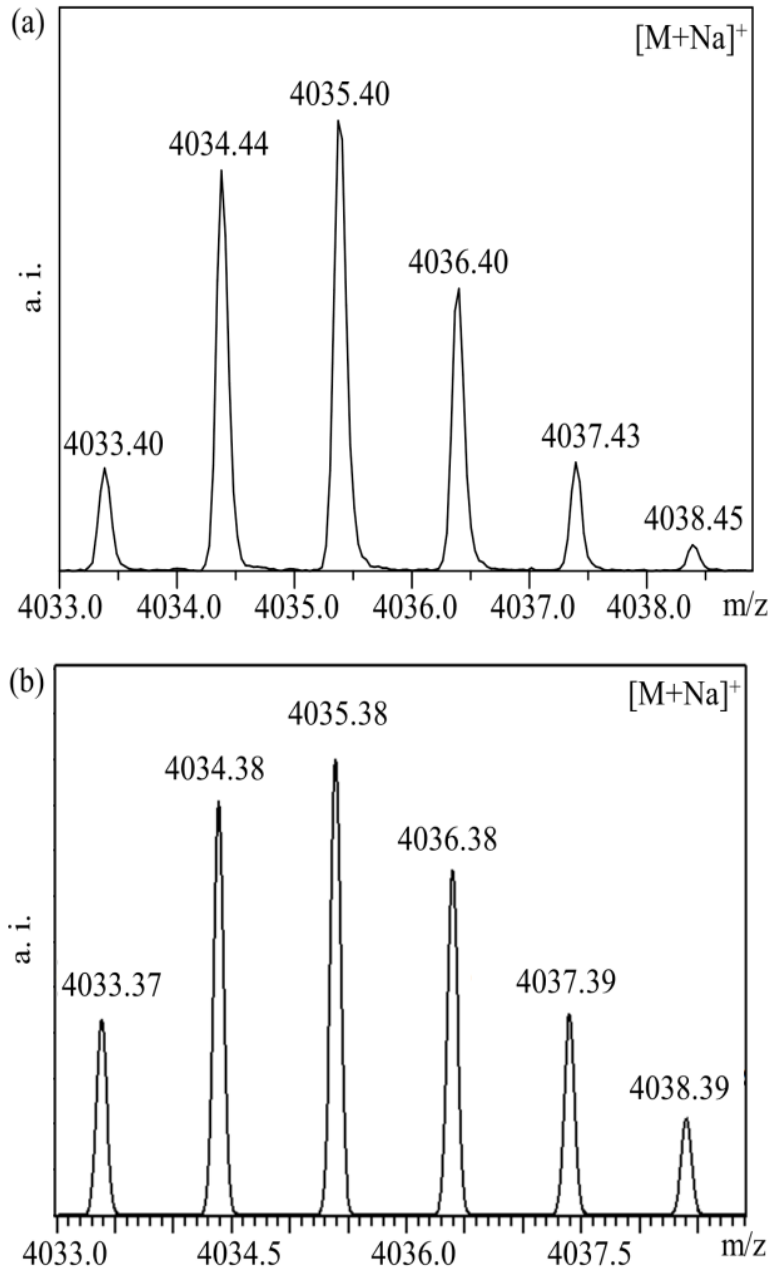

Fig. 6 Mass spectra of (a) experimental and (b) theoretical of $\left[\mathrm{Au}_{3} \mathrm{P} \mathrm{Z}_{3}\right]_{\mathrm{C} 10 \mathrm{TEG}}$

\section{CONCLUSION}

It was demonstrated that the conventional column gravity chromatography is not sufficient to obtain $\left[\mathrm{Au}_{3} \mathrm{Pz}_{3}\right]_{\mathrm{C} 10 \mathrm{TEG}}$ with high purity due to many limiting factors such as the type of adsorbent used, selection of correct solvents as the mobile phase and others. Hence, it can be concluded that size-exclusion chromatography can be used as an effective purification method with much more convenience and small consumption of solvents. In this study, $\left[\mathrm{Au}_{3} \mathrm{Pz}_{3}\right]_{\mathrm{C} 10 \mathrm{TEG}}$ as darkyellowish sticky solid with the presence of impurities was successfully purified via SEC for three cycles to give a pale-yellowish product. Moreover, the presence of impurities not only produced an anomalous peak in DSC thermogram but also shifted the melting point of $\left[\mathrm{Au}_{3} \mathrm{Pz}_{3}\right]_{\mathrm{P} 10 \mathrm{TEG}}$ to lower temperature. After the purification with $\mathrm{SEC},\left[\mathrm{Au}_{3} \mathrm{Pz}_{3}\right]_{\text {C10TEG }}$ was found to exhibit room temperature liquid crystalline properties with a mesophase range from 5.40 to $52.75^{\circ} \mathrm{C}$ $\left(\Delta \mathrm{T}=47.35^{\circ} \mathrm{C}\right)$ upon heating and 43.44 to $-7.19^{\circ} \mathrm{C}\left(\Delta \mathrm{T}=50.63{ }^{\circ} \mathrm{C}\right)$ upon cooling. For molecular weight determination, $\left[\mathrm{Au}_{3} \mathrm{Pz}_{3}\right]_{\mathrm{C} 10 \mathrm{TEG}}$ with the molecular formula of $\mathrm{C}_{189} \mathrm{H}_{345} \mathrm{Au}_{3} \mathrm{~N}_{6} \mathrm{O}_{45}$ for $[\mathrm{M}+\mathrm{Na}]^{+}$was shown at $4033.40 \mathrm{Da}$. Future research will challenge on the usage of the different type of detector such as refractive index (RI) detector in order to eliminate impurities that might not be detected by the current UV detector

\section{ACKNOWLEDGEMENTS}

The authors thank Universiti Teknologi Malaysia (UTM), Malaysia for characterization facilities. The authors also thank the Ministry of Higher Education (MOHE) through the Research University Grant Scheme (Vote No. GUP Q.J130000.2526.13H52) for the financial support.

\section{REFERENCES}

Barberá, J., Elduque, A., Giménez, R., Oro, L. A., Serrano, J. L. 1996 Pyrazolate "golden" rings: Trinuclear complexes that form columnar mesophases at room temperature. Angew. Chem. Int. Ed. 35, 2832-2835.

DeAngelis, N. J., Papariello, G. J. 1968. Differential scanning calorimetry: Advantages and limitations for absolute purity determinations. J. Pharm. Sci. 57, 1868-1872.

Hadjichristidis, N., Hirao, A., Tezuka, Y., Du Prez, F. 2011. Complex macromolecular architectures: Synthesis, characterization, and selfassembly. John Wiley \& Sons (Asia) Pte Ltd, p. 53-54.

Jalani, M. A., Yuliati, L., Endud, S., Lintang, H. O. 2014a. Synthesis of mesoporous silica nanocomposites for preparation of gold nanoparticles. Adv. Mat. Res. 925, 233-237.

Jalani, M. A., Yuliati, L., Lintang, H. O. 2014b. Thermal hydrogen reduction for synthesis of gold nanoparticles in the nanochannels of mesoporous silica composite. Jurnal Teknologi 70, 131-136.

Kim, S. J., Kang, S. H., Park, K. M., Kim, H., Zin, W. C., Choi, M. G., Kim, K. 1998. Trinuclear gold(I) pyrazolate complexes exhibiting hexagonal columnar mesophases with only three side chains. Chem. Mater. 10, 18891893.

Kishimura, A., Yamashita, T., Aida, T. 2005. Phosphorescent organogels via "metallophilic" interactions for reversible RGB-color switching. J. Am. Chem. Soc. 127, 179-183.

Kumar, S., Varshney, S. K. 2000. A room-temperature discotic nematic liquid crystal. Angew. Chem. Int. Ed. 39, 3140-3142.

La, M. G., Ardizzoia, G. A. 1997. The role of the pyrazolate ligand in building polynuclear transition metal systems. Prog. Inorg. Chem. 46, 151-238.

Lintang, H. O, Kinbara, K., Aida, T. 2011. Effect of acidic aqueous alcohol solution on template sol-gel synthesis of phosphorescent hexagonal mesoporous silica film nanocomposite. Mal. J. Fund. Appl. Sci. 7, 67-71.

Lintang, H. O, Kinbara, K., Aida, T. 2012b. Thermally resistive phosphorescent molecular assembly in the channels of mesoporous silica nanocomposites. 2012 Proceedings of International Conferences on Enabling Science and Nanotechnology (ESciNano). 5-7 January. Johor Bahru, Malaysia: IEEE, 6149684.

Lintang, H. O., Kinbara, K., Tanaka, K., Yamashita, T., Aida, T. 2010a. Self-repair of a one-dimensional molecular assembly in mesoporous silica by a nanoscopic template effect. Angew. Chem. Int. Ed. 49, 4241-4245.

Lintang, H. O., Kinbara, K., Tanaka, K., Yamashita, T., Aida, T. 2012a. Metalion permeation in congested nanochannels: The exposure effect of $\mathrm{Ag}^{+}$ions on the phosphorescent properties of a gold(I)-pyrazolate complex that is 
confined in the nanoscopic channels of mesoporous silica. Chem. Asian J. 2068-2072.

Lintang, H. O., Kinbara, K., Yamashita, T., Aida, T. 2010b. Heating effect of a one-dimensional molecular assembly on self-repairing capability in the nanoscopic channels of mesoporous silica. 2010 Proceedings of International Conferences on Enabling Science and Nanotechnology (ESciNano). 1-3 December. Kuala Lumpur, Malaysia: IEEE, 5700970.

Lintang, H. O., Yuliati, L., Endud, S. 2014. Phosphorescent sensing and imaging of temperature using mesoporous silica/gold nanocomposites. Mater. Res. Innov. 18, S6 444-448.

Liu, C. Y., Fechtenkötter, A., Watson, M. D., Müllen, K., Bard, A. J. 2003 Room temperature discotic liquid crystalline thin films of hexa-perihexabenzocoronene: Synthesis and optoelectronic properties. Chem. Mater. $15,124-130$

Luo, J., Zhao, B., Shao, J., Lim, K. A., Chan, H. S. O., Chi, C. 2009. Roomtemperature discotic liquid crystals based on oligothiophenes-attached and fused triazatruxenes. J. Mater. Chem. 19, 8327-8334.

Pavia, D. L., Engel, R. G., Kriz, G. S., Lampman, G. M. 2011. Introduction to organic laboratory techniques: A small scale approach. Belmont, CA: Brooks/Cole Cengage Learning, p. 237-258.

Pelletier, S. W., Chokshi, H. P., Desai, H. K. 1986. Separation of diterpenoid alkaloid mixtures using vacuum liquid chromatography. J. Nat. Prod. 49, 892-900.

Plato, C. 1972. Differential scanning calorimetry as a general method for determining purity and heat of fusion of high-purity organic chemicals: Application to 64 compounds. Anal. Chem. 44, 1531-1534.

Plato, C., Glasgow, A. R. Jr. 1969. Differential scanning calorimetry as a general method for determining the purity and heat of fusion of high-purity organic chemicals: Application to 95 compounds. Anal. Chem. 41, 330-336.
Sakurai, T., Tashiro, K., Honsho, Y., Saeki, A., Seki, S., Osuka, A., Muranaka, A., Uchiyama, M., Kim, J., Ha, S., Kato, K. 2011. Electron-or hole transporting nature selected by side-chain-directed $\pi$-stacking geometry: Liquid crystalline fused metalloporphyrin dimers. J. Am. Chem. Soc. 133, 6537-6540.

Sato, K., Itoh, Y., Aida, T. 2011. Columnarly assembled liquid-crystalline peptidic macrocycles unidirectionally orientable over a large area by an electric field. J. Am. Chem. Soc. 133, 13767-13769.

Schmidbaur, H. 2000. The aurophilicity phenomenon: A decade of experimental findings, theoretical concepts and emerging applications. Gold Bull. 33, 3-10.

Sidana, J., Joshi, L. K. 2013. Recycle HPLC: A powerful tool for the purification of natural products. Chromatogr. Res. Int. 1-7.

Targett, N. M., Kilcoyne, J. P., Green, B. 1979. Vacuum liquid chromatography: An alternative to common chromatographic methods. $J$. Org. Chem.44, 4962-4964

Torralba, M. C., Ovejero, P., Mayoral, M. J., Cano, M., Campo, J. A., Heras, J. V., Pinilla, E., Torres, M. R. 2004. Silver and gold trinuclear complexes based on 3-substituted or 3,5-disubstituted pyrazolato ligands. X-ray crystal structure of cyclo-tris $\{\mu-[3$,

5-bis(4-phenoxyphenyl)-1H-pyrazolato-kN1:kN2]\}trigold dichloromethane $\left(\left[\mathrm{Au}\left(\mu-\mathrm{pz}^{\mathrm{pP} 2}\right)\right]_{3}-\mathrm{CH}_{2} \mathrm{Cl}_{2}\right)$. Helv. Chim. Acta 87, 250-263.

Trofimenko, S. 1972. Coordination chemistry of pyrazole-derived ligands. Chem. Rev. 72, 497-509.

van Herrikhuyzen, J., Syamakumari, A., Schenning, A. P., Meijer, E. W. 2004. Synthesis of n-type perylene bisimide derivatives and their orthogonal selfassembly with p-type oligo( $p$-phenylene vinylene)s. J. Am. Chem. Soc. 126, 10021-10027.

Vékey, K., Telekes, A., Vertes, A. Medical applications of mass spectrometry. Chapter 5: Separation methods. Elsevier 2008, p. 61-92. 